\title{
ESTIMATING THE TOTAL LUBRICANT OIL CONSUMPTION RATE IN AGRICULTURAL TRACTORS
}

\author{
A. Calcante, M. Brambilla, C. Bisaglia, R. Oberti
}

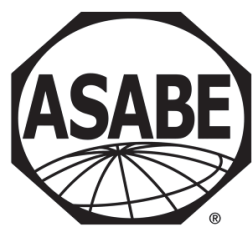

\begin{abstract}
Lubrication effectiveness is of paramount importance for the durability of machine components and efficient transmission of power. In addition to reducing the wear and friction of moving parts, lubricants remove potentially damaging heat and impurities and reduce the oxidation and corrosion of components. In agricultural tractors, lubricant oils are used in the engine, transmission, hydraulic system, front and rear axles, steering, and braking systems. This means that a substantial amount of oil must be changed at regular intervals, as recommended by manufacturers. This leads to a significant total oil consumption rate whose estimation is related to accurate accounting of tractor operating costs and to environmental impact analysis (e.g., LCA) of mechanized agricultural operations. The objective of this study was to propose a new general equation to estimate the total hourly lubricant oil consumption rate (HTOC) of agricultural tractors as a function of the rated engine power by extending the definition of lubricant oil consumption rate given by ASABE Standard D497.7. To this end, a linear regression analysis was conducted on a training dataset of 91 tractor models retrieved from OECD Code 2 reports. After validation with a dataset of 164 tractor models, the resulting equation for estimating the total lubricant oil consumption had an $R^{2}=0.75$ and prediction RMSE of $0.033 \mathrm{~kg} \mathrm{~h}^{-1}$. The equation was finally applied to an independent dataset of actual oil lubricant consumption rates obtained from a field survey of 118 agricultural tractors operating in northern Italy. Application of the equation to the field survey data showed an $R^{2}$ of 0.89 and RMSE of $0.010 \mathrm{~kg}$ $h^{-1}$ between predicted and actual values. Overall, the considered statistical indicators $\left(r, R^{2}, R M S E, P B I A S\right.$, and NSE) pointed to a satisfactory prediction capability of the equation.
\end{abstract}

Keywords. Agricultural tractors, Lubricant oil, Oil consumption, Mechanization costs.

A gricultural tractors are constantly improving their efficiency, cost-effectiveness, and operating performance, resulting in higher working speeds, wider versatility in coupling with machinery, and a better fit to a broad variability of operating conditions. To guarantee the efficiency and durability of such increasingly versatile and complex machines, regular maintenance of the lubrication system is vital. By limiting direct contact between the moving parts of machines, lubricant oils accomplish fundamental protective tasks: they reduce wear and friction between moving parts, reduce heat, remove the impurities caused by wear, and preserve metal surfaces from oxidation and corrosion by external agents (Booser, 1997).

In agricultural tractors, lubricant oils are used for the engine, transmission, front and rear axles, hydraulic system, steering system, and brakes. In addition to oil for lubrication,

Submitted for review in February 2018 as manuscript number MS 12803; approved for publication by the Machinery Systems Community of ASABE in December 2018

The authors are Aldo Calcante, Assistant Professor, Department of Agricultural and Environmental Sciences, Università degli Studi di Milano, Milan, Italy; Massimo Brambilla, Researcher, and Carlo Bisaglia, Senior Researcher, Consiglio per la Ricerca in Agricoltura e l'Analisi dell'Economia Agraria (CREA), Centro di Ricerca Ingegneria e Trasformazioni Agroalimentari (CREA-IT), Treviglio, Italy; Roberto Oberti, Associate Professor, Department of Agricultural and Environmental Sciences, Università degli Studi di Milano, Milan, Italy. Corresponding author: Aldo Calcante, via Celoria 2, IT-20133 Milan, Italy; phone+39-02-50316864; e-mail: aldo.calcante@unimi.it. the hydraulic system transmits power in the flow of pressurized oil to implements through hydraulic couplings, in addition to the mechanical tractor power supplied through the drawbar hitch and PTO shaft (Wertz et al., 1990; Bart et al. 2013). Lubricant oil also plays a key role in the latest generation of tractor transmissions, both in power-shift systems, where precise timing of the clutch operation is needed, and in continuously variable transmissions, where the main components are hydraulically driven (Kunz, 2006; Molari et al., 2008).

All this has led agricultural equipment manufacturers to pay more attention, on one hand, to new solutions enabling the optimization of lubrication and, on the other hand, to improvements in lubricant qualities, making lubricants comply with the increasing requirements of agricultural machines.

It is well known that lubricant oils, even in the most improved formulations, are subject to degradation due to a tractor's working hours and engine load, no matter the effectiveness of the filter technology. This degradation causes decay of the oil viscosity, accumulation of foreign impurities, i.e., carbon, water, oxides, and metal particles (Goering, 1992; Bart et al., 2013), and reduction of the detergent capability.

Whatever the case, the oil must be changed periodically. Typically, tractor engine oil is changed at intervals of 500 to $600 \mathrm{~h}$ of work (or every year), while the transmission oil is changed at intervals of 1200 to $1500 \mathrm{~h}$. Manufacturers' recommended oil change intervals must be carefully observed, and crankcases must be refilled when necessary (Goering, 1992). 
As an illustrative example, a 4WD tractor with a rated engine power of $100 \mathrm{~kW}$ requires a total amount of lubricant oil of more than $100 \mathrm{~L}$ (about $15 \mathrm{~L}$ for the engine, $80 \mathrm{~L}$ for the transmission and hydraulic system, and $10 \mathrm{~L}$ for the front and rear axles and steering system). Given such large amounts, it follows that the ability to estimate the total oil consumption rate during tractor operation would provide an important technical and economic parameter.

The effect of total oil consumption on a tractor's unitary operating costs (i.e., per hectare) can be directly estimated with the following equation (Srivastava et al., 2006; Calcante et al., 2017):

$$
C_{S L}=\frac{p_{L} \cdot \mathrm{HTOC}}{c_{a}}
$$

where

$C_{S L}=$ oil cost per hectare $\left(\$ \mathrm{ha}^{-1}\right)$

$p_{L}=$ price of oil $\left(\$ \mathrm{~kg}^{-1}\right)$

HTOC $=$ hourly total oil consumption rate $\left(\mathrm{kg} \mathrm{h}^{-1}\right)$

$c_{a}=$ actual field capacity during operation $\left(\mathrm{ha} \mathrm{h}^{-1}\right)$.

The most common equation for evaluating the oil consumption of tractors is defined by ASABE Standard D497.7, paragraph 3.4 (ASABE, 2015a). This equation establishes a linear model only for engine oil and estimates the volumetric oil consumption rate as a function of a diesel tractor's rated engine power:

$$
Q_{\text {LEng }}=0.00059 \cdot P+0.02169
$$

where

$Q_{\text {LEng }}=$ volumetric engine oil consumption rate $\left(\mathrm{L} \mathrm{h}^{-1}\right)$

$P=$ rated engine power $(\mathrm{kW})$.

The volumetric engine oil consumption rate $\left(Q_{\text {LEng }}\right)$ is defined as the volume per hour of engine crankcase oil replaced at the manufacturer's recommended change interval (ASABE, 2015a).

When lubricant oil consumption and related operating costs are estimated with equation 2 (i.e., assuming HTOC = $\rho_{\text {oil }} \cdot \mathrm{Q}_{\text {LEng }}$, where $\rho_{\text {oil }}$ is the density of the lubricant oil), a significant underestimation will occur because equation 2 was developed to account only for engine oil. An alternative method to calculate the hourly cost of engine oil is proposed by ASABE Standard EP496.3, paragraph 6.3.3 (ASABE, $2015 \mathrm{~b}$ ), which states that the total engine lubrication cost approaches $15 \%$ of the total fuel cost.

Given its fossil origin, mineral lubricant oil consumption is also evaluated with environmental impact methods. Life cycle assessment (LCA) is one of the most widely used methods to estimate the overall environmental impact associated with the use of a product during all stages of its life. When applied to agricultural production systems, LCA includes agricultural machines by taking account of the consumption of materials and energy and the direct emissions resulting from their use (Lovarelli et al., 2016). For the lubricant oil consumption by agricultural vehicles during their lifetime, the LCA approach refers to the values estimated by Ammann and Stadler (1998), who established an average engine oil consumption rate of $0.041 \mathrm{~kg} \mathrm{~h}^{-1}$ and an average hydraulic/transmission oil consumption rate of $0.044 \mathrm{~kg} \mathrm{~h}^{-1}$ from a ten-year survey of 46 tractors operating in Switzerland.

By adding these two consumption rates and assuming a tractor working life of 7000 h, Nemecek and Kägi (2007) estimated an expected total (i.e., lifetime) lubricant oil consumption of $598 \mathrm{~kg}$. In LCA inventories, this estimated lifetime oil consumption is typically referred to a unit machine mass. By considering an average tractor mass of $3000 \mathrm{~kg}$, Nemecek and Kägi (2007) extrapolated a raw value of 0.199 $\mathrm{kg}_{\text {oil }} \mathrm{kg}_{\text {tractor }}{ }^{-1}$, which is the current reference value suggested by LCA inventories (Nemecek and Kägi, 2007).

In this framework, the objective of this study is to propose and validate a new general equation to estimate the overall lubricant oil consumption in agricultural tractors. To do this, ASABE Standard D497.7 (ASABE, 2015a) was taken as a reference, and its approach was extended to all lubricant oils used in agricultural tractors. Specifically, the proposed equation allows computation of the hourly total oil consumption rate (HTOC) as a function of the tractor's rated engine power. The obtained results are intended to contribute to a more accurate accounting of lubricant oil consumption, both in mechanization cost computation and in environmental impact analysis of agricultural operations conducted by means of LCA or other similar methods.

\section{Materials ANd Methods}

This study was conducted in two phases. The first phase consisted of calibrating and validating an equation to estimate the overall lubricant oil consumption in agricultural tractors. The data used for this phase were retrieved from official technical reports. The second phase was a field application of the model using the actual oil lubricant consumption rates obtained from a survey of agricultural tractors currently operating in northern Italy.

\section{Calibration dataset Preparation}

A set of 255 agricultural tractor models (2WD, 4WD, and crawlers) from 22 different international manufacturers was selected to formulate an equation estimating the total oil consumption in tractors. The considered tractor models: (1) were of recent design (i.e., they were introduced on the market between 2000 and 2016), (2) covered a wide range of power (from 30 to $375 \mathrm{~kW}$ rated engine power), and (3) were equipped with different types of transmission (i.e., mechanical, partial or full power-shift, and continuously variable transmission).

The set of tractors was arbitrarily divided into four classes (labeled A, B, C and D) of rated engine power: class A (low power, 30 to $60 \mathrm{~kW}$ ) included 60 tractors with an average engine displacement of $3.46 \mathrm{~L}$, class B (medium power, 60 to $120 \mathrm{~kW}$ ) included 103 tractors with an average engine displacement of $5.26 \mathrm{~L}$, class $\mathrm{C}$ (high power, 120 to $200 \mathrm{~kW}$ ) included 49 tractors with an average engine displacement of $7.22 \mathrm{~L}$, and class D (very high power, $>200 \mathrm{~kW}$ ) included 43 tractors with an average engine displacement of $10.68 \mathrm{~L}$.

In ASABE Standard D497.7, paragraph 3.4 (ASABE, $2015 \mathrm{a}$ ), the engine oil consumption rate is defined as the volume per hour of engine oil in the crankcase replaced at the 
manufacturer's recommended change interval. By extending this definition, the oil consumption rates for the gearbox, rear and front axles and final drives, and hydraulic and steering systems were similarly considered in this study. These values were hence computed as the volume of oil (L) in the specific subsystem crankcase and the associated oil change interval (h) recommended by the manufacturer.

In the first phase of this study, all data were retrieved from official reports of tests conducted in accordance with OECD Code 2 (OECD, 2017) for agricultural tractors. Following the ASABE approach, the hourly total oil consumption rate $\left(\mathrm{HTOC}, \mathrm{kg} \mathrm{h}^{-1}\right.$ ) for a generic tractor was obtained as:

$$
\begin{aligned}
\text { HTOC } & =\rho_{\text {oil }} \cdot\left(\frac{\mathrm{ELO}}{\mathrm{ELOCI}}+\frac{\mathrm{GLO}}{\mathrm{GLOCI}}+\frac{\mathrm{HSO}}{\mathrm{HSOCI}}\right. \\
& \left.+\frac{\mathrm{RAFDO}}{\mathrm{RAFDOCI}}+\frac{\text { FAFDO }}{\text { FAFDOCI }}+\frac{\mathrm{SO}}{\mathrm{SOCI}}\right)
\end{aligned}
$$

where

$\rho_{\text {oil }}=0.88 \mathrm{~kg} \mathrm{~L}^{-1}$ (Bart et al., 2013)

$\mathrm{ELO}=$ engine lubricating oil amount $(\mathrm{L})$

ELOCI $=$ engine lubricating oil change interval $(\mathrm{h})$

$\mathrm{GLO}=$ gearbox oil amount $(\mathrm{L})$

GLOCI = gearbox oil change interval $(\mathrm{h})$

$\mathrm{HSO}=$ hydraulic system oil amount (L)

HSOCI $=$ hydraulic system oil change interval $(\mathrm{h})$

RAFDO $=$ rear axle and final drive oil amount (L)

RAFDOCI $=$ rear axle and final drive oil change interval (h)

FAFDO $=$ front axle and final drive oil amount (L)

FAFDOCI $=$ front axle and final drive oil change interval (h)

$\mathrm{SO}=$ steering system oil amount $(\mathrm{L})$

$\mathrm{SOCI}=$ steering system oil change interval $(\mathrm{h})$.

For every tractor, the computed HTOC value was associated with the corresponding rated engine power, and the relationship was statistically analyzed.

\section{EQUATION CALIBRATION AND VALIDATION}

To define a linear equation to estimate the total lubricant oil consumption rate, the obtained dataset was split into two subsets: a training set for calibrating the equation coefficients by means of regression analysis, and a validation set to validate the equation by evaluating its prediction error. In accordance with commonly adopted approaches (e.g., Rawlings et al., 2001; Hastie et al., 2008), the tractor data for the training set were randomly selected from tractors in the dataset that met the following three constraints: (1) the values of the modeled variables (HTOC and rated engine power) had to span the range observed in the complete dataset, (2) the distribution of the modeled values of HTOC and rated engine power had to comply with the normality condition required by linear regression analysis (Shapiro-Wilk test), and (3) the number of tractors in the training set had to be at least one-third of the total dataset. As a result, the values of HTOC and rated engine power of 91 tractors were selected as the training set for the equation, while the remaining 164 tractors were included in the validation set.
Linear regression analysis (LRA) between the rated engine power (the estimator) and HTOC data was conducted on the training set by applying the LRA procedure of Minitab 17.0 (Minitab, 2010) to the following equation:

$$
\mathrm{HTOC}=\beta_{0}+\beta \cdot P
$$

where

$\beta_{0}=$ intercept term of regression equation $\left(\mathrm{kg} \mathrm{h}^{-1}\right)$

$\beta=$ regression equation slope coefficient $\left(\mathrm{kg} \mathrm{kW}^{-1} \mathrm{~h}^{-1}\right)$

$P=$ rated engine power $(\mathrm{kW})$.

LRA enabled finding the values of coefficients $\beta_{0}$ and $\beta$ that minimize the sum of the squared residuals computed for all 91 pairs of data in the training set.

The prediction capability of equation 4 was validated by applying it to the data for the 164 tractors in the validation set. To this end, the oil consumption rate values predicted by equation 4 and the corresponding values retrieved from the OECD Code 2 reports were statistically analyzed. The quantitative results were evaluated with Pearson's correlation coefficient (r), the coefficient of determination $\left(R^{2}\right)$, the root mean square error (RMSE), the percent bias of prediction (PBIAS), and the dimensionless Nash-Sutcliffe efficiency (NSE) (Moriasi et al., 2007). Ideally, the RMSE and PBIAS values are 0 , and low values indicate an accurate prediction. NSE values range between $-\infty$ and 1 , and values between 0 and 1 are generally considered an indication of satisfactory prediction.

\section{Field SURVEY APPLICATION}

As a real application for the equation determined above, a field survey was conducted to obtain an independent set of data representing 118 operating tractors $(2 \mathrm{WD}, 4 \mathrm{WD}$, and crawlers) in northern Italy with the aim of retrieving actual values of lubricant oil consumption observed in the field. The field data were obtained from three sources: (1) large farms, (2) contractor companies, and (3) dealership and authorized workshop databases (Buckmaster, 2003; Calcante et al., 2013; Lips, 2013; Hawkins and Buckmaster, 2015). For the purposes of this study, these data were assumed to be reliable because they were all obtained from subjects who kept traceable machinery records as part of a broader management accounting system (Morris, 1988).

All 118 tractors considered in the field survey were models introduced on the market between 2000 and 2016. Of them, 97 tractors $(82 \%)$ corresponded to models not included in the original dataset (i.e., the 255 OECD reports) used to determine the equation. Their average engine power was $131.3 \mathrm{~kW}$ (33.1 kW minimum, $301.5 \mathrm{~kW}$ maximum), and their average accumulated working hours were $8033 \mathrm{~h}$ (2378 $\mathrm{h}$ minimum, 23,550 $\mathrm{h}$ maximum).

The actual hourly total oil consumption rate (HTOC, $\mathrm{kg}$ $\mathrm{h}^{-1}$ ) was calculated for each tractor by applying the following equation:

$$
\mathrm{HTOC}=\rho_{\text {oil }} \cdot\left(\frac{\mathrm{TOC}}{\mathrm{HAcc}}\right)
$$

where TOC is the accumulated lubricant oil quantity (from the first oil change until the last, including possible refilling) 
observed at the time of the survey (L), and HAcc is the accumulated number of working hours shown on the engine hour meter and recorded at the time of the survey (h).

The ability of equation 4 to estimate the actual HTOC values resulting from the field survey of the 118 operating tractors was quantitatively evaluated by applying the same statistical indicators described in the preceding section on equation calibration and validation.

\section{RESUlTS AND DisCuSSION DATASET DESCRIPTION}

For all 255 tractors used in the first phase of the study, data were available for rated engine power, engine displacement, engine oil volume, and gearbox oil volume with their change intervals. Tables 1 and 2 summarize these data subdivided into the four power classes. As expected, the amount of oil dramatically increased with the rated engine power of the tractors. In contrast, the change interval of engine oil showed less variation (typically 400 to $600 \mathrm{~h}$ ), except for low-power tractors, which have significantly shorter change intervals (typically 200 to $300 \mathrm{~h}$ ). Gearbox oil had longer change intervals (typically 1000 to $1500 \mathrm{~h}$ ), with shorter intervals for low- and medium-power tractors (rated engine power from 30 to $120 \mathrm{~kW}$ ) than for medium- and high-powered tractors (rated engine power $>120 \mathrm{~kW}$ ).

Other parameters (e.g., the amounts of hydraulic system oil, front and rear axle oil, and steering oil) were not always available as separate values due to the design characteristics of specific machines that share the oil for the hydraulic system and gearbox from a common oil sump. Consequently, for this group of machines ( 226 tractors, i.e., about $88 \%$ of the dataset), it was only possible to extract a combined value of oil amount (i.e., GLO + HSO). Similarly, for 238 tractors (93\% of the dataset), the rear axle and its final drives were lubricated by the gearbox oil, while the amount of lubricating oil for the front axle and its final drives was available only for the $2174 \mathrm{WD}$ tractors ( $85 \%$ of the dataset). Table 2 shows the values for the tractors for which these parameters were available separately.

Overall, the dataset illustrates the significant influence of lubricated subsystems, other than the engine, in determining a tractor's oil consumption. For example, in medium- and high-powered tractors (classes $\mathrm{C}$ and $\mathrm{D}$ in tables 1 and 2) the hydraulic system and gearbox oil each contributed at least 1.5 times the engine oil contribution to the HTOC value.

\section{EQUATION CALIBRATION}

Table 3 describes the composition of the training set (91 tractors) used to obtain the linear equation between rated engine power and HTOC. Table 3 shows the homogenous distribution of the training samples among the power classes
Table 2. Means \pm standard deviations for parameters available separately for a subset of the 255 considered tractors.

\begin{tabular}{cccc}
\hline $\begin{array}{c}\text { Power } \\
\text { Class }\end{array}$ & $N$ & $\begin{array}{c}\text { RAFDO } \\
(\mathrm{L})\end{array}$ & $\begin{array}{c}\text { RAFDOCI } \\
(\mathrm{h})\end{array}$ \\
\hline A & 5 & $6.72 \pm 8.0$ & $1080 \pm 109.5$ \\
B & 5 & $7.09 \pm 5.8$ & $1090 \pm 279.0$ \\
C & 2 & $26.5 \pm 16.3$ & $1250 \pm 106.1$ \\
D & 5 & $26.0 \pm 10.8$ & $1700 \pm 671.0$ \\
\hline & & HSO & HSOCI \\
& & $(\mathrm{L})$ & - \\
\hline A & 0 & - & $1167 \pm 289.0$ \\
B & 3 & $61.3 \pm 10.0$ & $1088 \pm 180.8$ \\
C & 8 & $89.5 \pm 15.9$ & $1467 \pm 265.7$ \\
D & 18 & $174.4 \pm 69.7$ & SOCI \\
\hline & & SO & $(\mathrm{h})$ \\
\hline A & 24 & $2.30 \pm 0.9$ & $925.0 \pm 377.9$ \\
B & 5 & $2.80 \pm 1.5$ & $1040 \pm 329.0$ \\
C & 0 & - & - \\
D & 0 & - & - \\
\hline & & FAFDO & FAFDOCI \\
\hline A & 57 & $(\mathrm{~L})$ & $1082 \pm 229.9$ \\
B & 97 & $9.20 \pm 2.8$ & $1134 \pm 181.9$ \\
D & 46 & $24.1 \pm 24.0$ & $1182 \pm 389.3$ \\
\hline
\end{tabular}

Table 3. Means \pm standard deviations of rated engine power and hourly total oil consumption rate (HTOC) of the training set of 91 tractors used for calibration of the equation.

\begin{tabular}{cccc}
\hline $\begin{array}{c}\text { Power } \\
\text { Class }\end{array}$ & $N$ & $\begin{array}{c}\text { Power } \\
(\mathrm{kW})\end{array}$ & $\begin{array}{c}\text { HTOC } \\
\left(\mathrm{kg} \mathrm{h}^{-1}\right)\end{array}$ \\
\hline A & 20 & $46.7 \pm 9.1$ & $0.072 \pm 0.03$ \\
B & 35 & $87.3 \pm 16.7$ & $0.090 \pm 0.03$ \\
C & 23 & $163.1 \pm 24.8$ & $0.145 \pm 0.03$ \\
D & 13 & $245.3 \pm 30.2$ & $0.172 \pm 0.02$ \\
\hline
\end{tabular}

and highlights the overall increasing trend of lubricant oil consumption with engine power.

Figure 1 shows the corresponding linear regression line for the training dataset. LRA identified the following linear equation to estimate the tractor's hourly total oil consumption as a function of rated engine power:

$$
\text { HTOC }=\left(0.000556 \frac{\mathrm{kg}}{\mathrm{kW} \cdot \mathrm{h}}\right) \cdot P+0.04487 \frac{\mathrm{kg}}{\mathrm{h}}
$$

The coefficient of determination $\left(\mathrm{R}^{2}\right)$ for the regression was 0.69 . The standard error of the intercept $\left(\beta_{0}\right)$ and slope $(\beta)$ of the equation were $\pm 5.5 \cdot 10^{-3} \mathrm{~kg} \mathrm{~h}^{-1}$ and $\pm 4.0 \cdot 10^{-5} \mathrm{~kg}$ $\mathrm{kW}^{-1} \mathrm{~h}^{-1}$, respectively. These error values are less than $15 \%$ and $10 \%$ respectively, of the coefficients in equation 6 , which provides a rough indication of the robustness of the equation. The coefficients in equation 6 can be compared to the coefficients in the equation from ASABE Standard D497.7 (ASABE, 2015a), i.e., equation 2, multiplied by the estimated oil density of $0.88 \mathrm{~kg} \mathrm{~L}^{-1}$. This comparison shows that the slope coefficient in equation $6\left(0.000556 \mathrm{~kg} \mathrm{~kW}^{-1}\right.$

Table 1. Means \pm standard deviations for parameters common to all 255 considered tractors.

\begin{tabular}{|c|c|c|c|c|c|c|c|c|}
\hline $\begin{array}{c}\text { Power } \\
\text { Class }\end{array}$ & $N$ & $\begin{array}{c}\text { Power } \\
(\mathrm{kW})\end{array}$ & $\begin{array}{c}\text { Engine } \\
\text { Displacement } \\
\text { (L) }\end{array}$ & $\begin{array}{c}\text { ELO } \\
\text { (L) }\end{array}$ & $\begin{array}{l}\text { ELOCI } \\
\text { (h) }\end{array}$ & $\begin{array}{c}\text { GLO } \\
\text { (L) }\end{array}$ & $\begin{array}{l}\text { GLOCI } \\
\text { (h) }\end{array}$ & $\begin{array}{l}\text { HTOC } \\
\left(\mathrm{kg} \mathrm{h}^{-1}\right)\end{array}$ \\
\hline $\mathrm{A}$ & 60 & $48.2 \pm 7.5$ & $3.46 \pm 0.67$ & $9.0 \pm 2.3$ & $294.2 \pm 131.8$ & $40.7 \pm 12.4$ & $1113.3 \pm 395.1$ & $0.078 \pm 0.025$ \\
\hline B & 103 & $86.5 \pm 15.7$ & $5.26 \pm 1.26$ & $13.4 \pm 4.4$ & $445.9 \pm 138.7$ & $32.8 \pm 17.4$ & $1164.1 \pm 237.9$ & $0.089 \pm 0.029$ \\
\hline $\mathrm{C}$ & 49 & $158.4 \pm 23.1$ & $7.22 \pm 1.02$ & $21.4 \pm 3.7$ & $473.5 \pm 80.6$ & $111.6 \pm 41.6$ & $1404.1 \pm 293.7$ & $0.142 \pm 0.039$ \\
\hline $\mathrm{D}$ & 43 & $264.0 \pm 43.6$ & $10.68 \pm 2.38$ & $32.7 \pm 11.3$ & $480.8 \pm 84.8$ & $155.4 \pm 82.4$ & $1530.2 \pm 247.4$ & $0.210 \pm 0.038$ \\
\hline
\end{tabular}




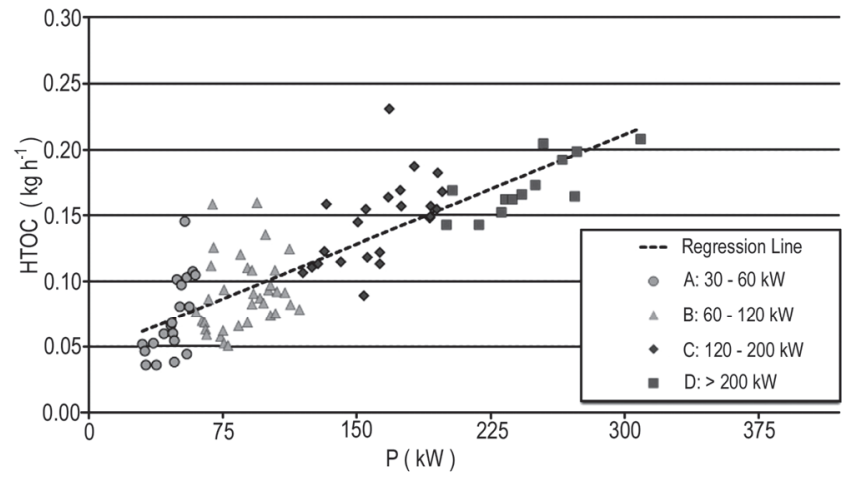

Figure 1. Total hourly oil consumption (HTOC) for 91 tractors (training set) from four power classes used to determine a linear regression equation for estimating tractor total hourly oil consumption (HTOC) as a function of rated engine power. Regression $R^{2}=0.69$.

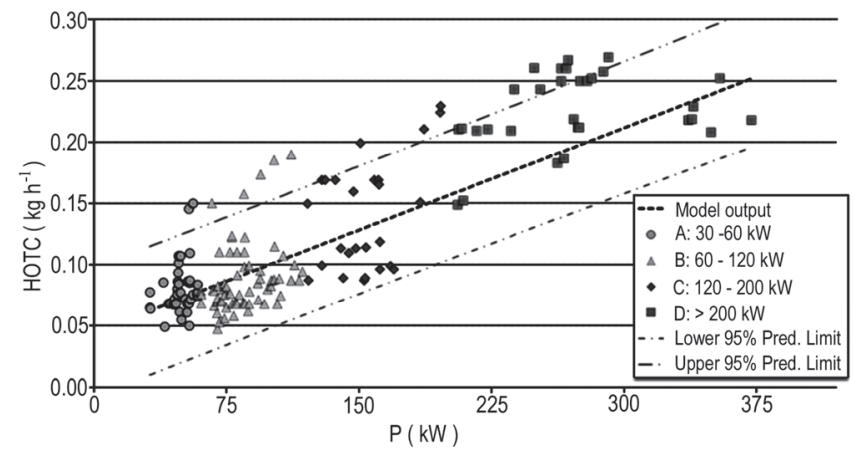

Figure 2. Computed hourly total oil consumption (HTOC) from OECD Code 2 reports as a function of rated engine power for 164 tractors in the validation set and the corresponding equation output (bold line). Upper and lower $95 \%$ prediction limits of predicted values are also shown. $R^{2}=0.87$ for fit of data to the prediction equation (eq. 6).

$\mathrm{h}^{-1}$ ) is similar to (i.e., 1.07 times) the corresponding slope coefficient from equation $2\left(0.000519 \mathrm{~kg} \mathrm{~kW}^{-1} \mathrm{~h}^{-1}\right)$, and the intercept coefficient in equation $6\left(0.04487 \mathrm{~kg} \mathrm{~h}^{-1}\right)$ is larger than (i.e., 2.35 times) the corresponding intercept coefficient from equation $2\left(0.0191 \mathrm{~kg} \mathrm{~h}^{-1}\right)$.

The obtained equation relies on easily accessible data and complies with the requirements of mathematical simplicity, meaning "simple to fit, simple to interpret, simple to justify, and simple to apply" (Montgomery et al., 2001; Schabenberger and Pierce, 2002). It is important to note the wide variability of the average HTOC values over the different power classes of the tractors in the training set (last column in table 3). This behavior was obviously reflected in the prediction ability of the equation. In fact, in figure 2, the $95 \%$ prediction interval of the calibrated equation, i.e., the range of HTOC values in which $95 \%$ of new observations (new tractors) are expected to fall, was within $\pm 0.05 \mathrm{~kg} \mathrm{~h}^{-1}$ for all four power classes. This means that, for very high-power tractors, the expected uncertainty of prediction is about $\pm 30 \%$ of the average HTOC value. For low-power tractors, this uncertainty is about $\pm 70 \%$ of the average HTOC value.

\section{EQUATION VALIDATION}

For validation of the model, equation 6 was applied to the 164 tractors in the validation set. In figure 2, the actual HTOC data of the validation set are plotted as a function of

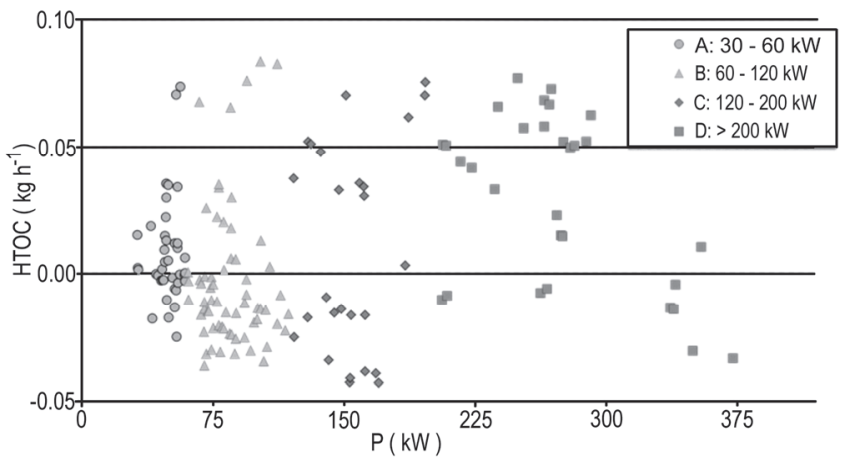

Figure 3. Model residuals (HTOC computed from OECD Code 2 reports - model-predicted HTOC) for 164 tractors in the validation set for different classes of rated engine power.

rated engine power, together with the HTOC predicted with the calibrated equation. The data for tractors in the four power classes appear to fit well with the equation prediction, with a coefficient of determination $\left(\mathrm{R}^{2}\right)$ of the measured and predicted HTOC values of 0.75 . Figure 2 also shows the $95 \%$ prediction interval for values predicted by the equation. The plot shows 19 tractors (11.6\% of the validation set) with HTOC values that substantially deviate from the behavior predicted by the equation and fall above the upper prediction limit. These data refer to tractors with specific technical characteristics, including eleven tractors equipped with hydraulic continuously variable transmissions (seven midpower tractors, i.e., rated engine power of 60 to $120 \mathrm{~kW}$, and four high-power tractors, i.e., rated engine power of 120 to $200 \mathrm{~kW}$ ) and eight very high-power (rated engine power > $200 \mathrm{~kW}$ ) articulated tractors with particularly large engine displacement.

Figure 3 plots the equation residuals (i.e., computed HTOC from OECD Code 2 reports - model-predicted HTOC) as a function of rated engine power. The plot highlights a uniform distribution of the residuals with no regular pattern, which indicates that the equation prediction is unbiased. This was confirmed statistically with a Tukey test applied to the residuals obtained for the four power classes, which turned out to have no significant differences.

During the validation, the correlation coefficient (r) between the HTOC computed from OECD Code 2 reports and the HTOC predicted by equation 6 was found to be 0.87 , the RMSE achieved a value of $0.033 \mathrm{~kg} \mathrm{~h}^{-1}$, and the PBIAS was $6.1 \%$. This means that a good prediction was achieved, with an underestimation bias that can be ascribed to the fact that, particularly for tractors with the highest power (class D; fig. 2), the equation underestimated the HTOC of the validation set. The NSE value for this set of data was found to be 0.7 .

\section{Field SURVEY APPLICATION}

Evaluation of the model performance using the set of 118 tractors (2WD, 4WD, and crawlers) in operation in northern Italy revealed a correlation coefficient (r) of 0.96 , a coefficient of determination $\left(\mathrm{R}^{2}\right)$ equal to 0.89 , the RMSE was $0.010 \mathrm{~kg} \mathrm{~h}^{-1}$, and the PBIAS reached a value of $-3 \%$. Figure 4 shows that the predicted versus measured oil consumption data were well placed along the 1:1 reference line. 


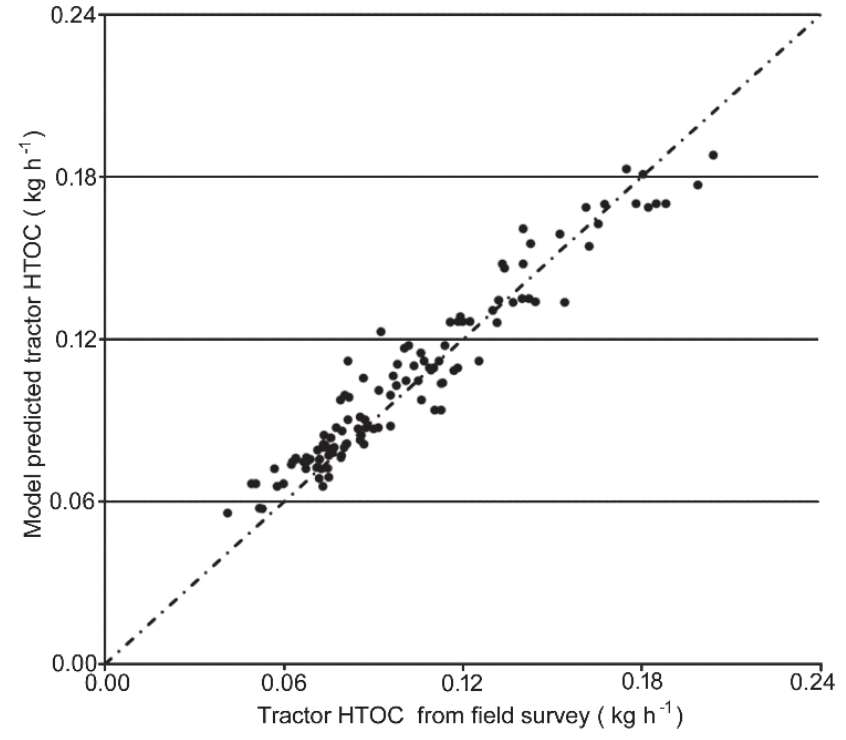

Figure 4. Scatterplot of predicted hourly total oil consumption (HTOC) calculated with equation 6 versus HTOC values derived from a field survey of 118 tractors in northern Italy. Dashed line is 1:1 line.

Of the computed statistical indexes, Pearson's correlation coefficient ( $\mathrm{r}$ ) and the $\mathrm{R}^{2}$ value were high. The value of $\mathrm{r}$ was 0.96 , indicating the high degree to which the simulation reproduced the trends in the observed data (Anderton et al., 2002), and the $\mathrm{R}^{2}$ value was high as well, reaching 0.89 . The PBIAS value was $-3.0 \%$, and this negative value indicates a slight overestimation bias of the actual HTOC values. Notwithstanding that the optimal PBIAS value is 0.0 , the low magnitude of the values resulting from both the equation and the field survey data indicate that the model simulation can be considered acceptable (Moriasi et al., 2007). The RMSE of the HTOC predicted by equation 6 for the 118 tractors in the field survey data was $0.010 \mathrm{~kg} \mathrm{~h}^{-1}$, which is $8.9 \%$ of the mean HTOC value for the whole validation set $(0.112 \mathrm{~kg}$ $\left.\mathrm{h}^{-1}\right)$. The NSE value was 0.9 .

The significance of the results was confirmed by application of the Mann-Whitney test (because the distribution of samples was not normal according to the Shapiro-Wilk test) on two independent populations (significance $\alpha=0.05 ; \mathrm{p}=$ 0.284 ). Based on the results, it can be asserted that the differences between the two populations (actual HTOC and predicted HTOC; fig. 4) are not significant, and equation 6 is therefore capable of predicting the total oil consumption of an agricultural tractor as a function of its rated engine power with a high level of reliability.

The field survey data showed a better correlation than the calibration dataset with the results predicted by equation 6 . This is probably due to the limited number of tractors with hydraulic continuously variable transmissions included in the survey data and the absence of articulated tractors. This reflects the fact that these types of machines are not widespread in the area considered by the survey, and therefore it was difficult to obtain field data for them.

Finally, for illustrative purposes, we considered four sample tractors (not included in the field survey of 118 tractors) that represented the four classes of rated engine power and were introduced to the market in the last five years. Based on their actual oil consumption, we computed their actual HTOC values and compared the results with the values estimated by our equation (eq. 6), by the ASABE equation (eq. 1), and by the LCA equation proposed by Ammann and Stadler (1998). Table 4 shows the results obtained with the three equations. The deviations of equation 6 were within $\pm 10 \%$ for all four tractors. As expected, because the ASABE equation only considers the engine oil, it significantly underestimated the total oil consumption. In contrast, the LCA inventories greatly overestimated (by almost 100\%) the actual oil consumption, except for the low-power tractor.

For the same four tractors, table 5 shows a comparison between the cost for lubricants obtained with ASABE Standard EP496.3, paragraph 6.3.3 (ASABE, 2015b) and the value obtained by multiplying the oil price by the hourly consumption predicted with equation 6 . Two different price scenarios for lubricant oil were considered: $5.3 \mathrm{USD} \mathrm{kg}^{-1}$ and $4.0 €$ $\mathrm{kg}^{-1}$ for the U.S. and Europe, respectively. Because the method proposed by ASABE Standard EP496.3 (ASABE,

Table 4. Application of different equations for estimating the total oil consumption rate in four representative tractors.

\begin{tabular}{|c|c|c|c|c|c|c|}
\hline \multirow[b]{2}{*}{ Tractor } & \multirow{2}{*}{$\begin{array}{c}\text { Power } \\
(\mathrm{kW})\end{array}$} & \multirow{2}{*}{$\begin{array}{c}\text { Tractor Mass } \\
(\mathrm{kg})\end{array}$} & \multirow{2}{*}{$\begin{array}{c}\text { Actual HTOC } \\
\left(\mathrm{kg} \mathrm{h}^{-1}\right)\end{array}$} & \multicolumn{3}{|c|}{ Error from Actual HTOC (\%) ${ }^{[\mathrm{a}]}$} \\
\hline & & & & Equation 6 & ASABE Model $^{[\mathrm{b}]}$ & LCA Inventories $^{[\mathrm{c}]}$ \\
\hline 1 & 48 & 2714 & 0.075 & $-4.6 \%$ & $-41.3 \%$ & $+4.9 \%$ \\
\hline 2 & 86 & 5190 & 0.085 & $+9.0 \%$ & $-25.0 \%$ & $+98.1 \%$ \\
\hline 3 & 156 & 7350 & 0.134 & $-1.8 \%$ & $-25.3 \%$ & $+74.9 \%$ \\
\hline 4 & 264 & 12190 & 0.208 & $-7.9 \%$ & $-24.9 \%$ & $+88.7 \%$ \\
\hline
\end{tabular}

[a] Error $=100 \%$ (predicted HTOC - actual HTOC) / actual HTOC.

[b] ASABE Standard D497.7 (ASABE, 2015a); equation considers only engine oil.

[c] Based on equation derived from Ammann and Stadler (1998).

Table 5. Comparison between lubricant costs estimated with equation 6 and with ASABE Standard EP496.3 for four representative tractors.

\begin{tabular}{|c|c|c|c|c|c|c|}
\hline \multirow[b]{2}{*}{ Tractor } & \multirow{2}{*}{$\begin{array}{c}\text { Power } \\
(\mathrm{kW})\end{array}$} & \multirow{2}{*}{$\begin{array}{c}\text { Average } \\
\text { Engine Load } \\
(\% \text { of power })\end{array}$} & \multicolumn{2}{|c|}{$\begin{array}{l}\text { Cost of Lubricant Oil } \\
\left(\text { U.S. Scenario, } \$ \mathrm{~h}^{-1} \text { ) }\right.\end{array}$} & \multicolumn{2}{|c|}{$\begin{array}{c}\text { Cost of Lubricant Oil } \\
\left(\text { European Scenario, } € \mathrm{~h}^{-1}\right)\end{array}$} \\
\hline & & & Equation 6 & ASABE Model ${ }^{[\mathrm{a}]}$ & Equation 6 & ASABE Model $^{[\mathrm{a}]}$ \\
\hline \multirow[t]{2}{*}{1} & 48 & 30 & 0.38 & 0.55 & 0.28 & 0.73 \\
\hline & & 70 & & 0.96 & & 1.28 \\
\hline \multirow[t]{2}{*}{2} & 86 & 30 & 0.49 & 0.98 & 0.37 & 1.31 \\
\hline & & 70 & & 1.72 & & 2.30 \\
\hline \multirow[t]{2}{*}{3} & 156 & 30 & 0.70 & 1.78 & 0.52 & 2.37 \\
\hline & & 70 & & 3.12 & & 4.17 \\
\hline \multirow[t]{2}{*}{4} & 264 & 30 & 1.02 & 3.01 & 0.76 & 4.01 \\
\hline & & 70 & & 5.29 & & 7.05 \\
\hline
\end{tabular}

ASABE Standard EP496.3, paragraph 6.3.3 (ASABE, 2015b); equation considers only engine oil. 
2015b) depends on tractor fuel consumption, we assumed two average engine loads: one representative of typical use in light operations (average load $=30 \%$ of rated power, partial throttle multiplier $=0.75$ ), and one representative of use in medium to heavy operations (average load $=70 \%$ of rated power, partial throttle multiplier $=0.90$ ). The fuel consumption was estimated by multiplying the corresponding engine power by the specific fuel consumption obtained with ASABE Standard D497.7, paragraph 3.3.3 (ASABE, 2015a). The assumed diesel fuel price was 0.6 USD L $^{-1}$ and $0.8 € \mathrm{~L}^{-1}$ for the U.S. and Europe, respectively.

The results show large deviations between the two approaches. In particular, the lubricant costs obtained with ASABE Standard EP496.3, paragraph 6.3.3 (ASABE, 2015b) are significantly higher (about 1.5 to 9 times) than the costs calculated with equation 6 , although the model in ASABE Standard EP496.3 only accounts for engine oil cost.

\section{CONCLUSIONS}

The objective of this study was to determine and validate a new general equation to estimate the hourly total oil consumption rate (HTOC) of agricultural tractors. The HTOC value for a tractor was defined by extending the definition of engine oil consumption rate given by ASABE Standard D497.7, paragraph 3.4 (ASABE, 2015a). The obtained equation was first validated with a set of 164 observations computed from OECD Code 2 reports and subsequently applied to a dataset of actual oil consumption rates measured in a field survey of 118 tractors currently operating in northern Italy.

The resulting equation estimated the actual oil consumption of the validation set with a coefficient of determination $\left(\mathrm{R}^{2}\right)$ of 0.75 , which increased to 0.89 when applied to the field survey data. Analysis of the predicted and actual oil consumption rates for a large dataset confirmed the statistical soundness ( $r$, $\mathrm{R}^{2}$, RMSE, PBIAS, and NSE) of the proposed equation.

The prediction accuracy of the model equation was significantly better with the field survey data than with the calibration dataset. This is probably because the field survey was conducted in a region characterized by a limited number of tractors with hydraulic continuously variable transmissions and a scarcity of articulated tractors. In fact, these two types of tractors gave the poorest prediction capability during the equation calibration. This could be addressed in future work by a study dedicated to these particular machines, especially those with very high rated power.

Finally, for illustrative purposes, the equation output was compared with results obtained from two other available methods (ASABE and LCA equations), and a much improved prediction capability was obtained. In particular, a comparative analysis of lubricant costs with equation 6 and with ASABE Standard EP496.3, paragraph 6.3.3 (ASABE, 2015b) indicated dramatic differences (from 1.5 to 9 times). This suggests the need for a possible update of the models in the ASABE standard.

Based on the above findings, the equation presented in this article is proposed for use in technical and economic analyses for estimating the operating costs or the environmental impact of tractor operations.

\section{REFERENCES}

Ammann, H., \& Stadler, E. (1998). Technische und organisatorische Aspekte des Traktoren einsatzes (Technical and organizational aspects of tractor use). FAT-Berichte No. 511. Zürich, Switzerland: Agroscope Reckenholz-Tänikon Research Station.

Anderton, S., Latron, J., \& Gallart, F. (2002). Sensitivity analysis and multi-response, multi-criteria evaluation of a physically based distributed model. Hydrol. Proc., 16(2), 333-353. https://doi.org/10.1002/hyp.336

ASABE. (2015a). Standard D497.7 MAR2011 (R2015): Agricultural machinery management data. St. Joseph, MI: ASABE.

ASABE. (2015b). Standard EP496.3 FEB2006 (R2015): Agricultural machinery management. St. Joseph, MI: ASABE.

Bart, J. C., Gucciardi, E., \& Cavallaro, S. (2013). Biolubricants: Science and technology. Cambridge, UK: Woodhead Publishing. https://doi.org/10.1533/9780857096326

Booser, E. R. (1997). Tribology data handbook: An excellent friction, lubrication, and wear resource. Boca Raton, FL: CRC Press. https://doi.org/10.1201/9781420050479

Buckmaster, D. R. (2003). Benchmarking tractor costs. Appl. Eng. Agric., 19(2), 151-154. https://doi.org/10.13031/2013.13104

Calcante, A., Brambilla, M., Bisaglia, C., \& Oberti, R. (2017). Proposal to estimate the engine oil consumption in agricultural tractors. Appl. Eng. Agric., 33(2), 191-194. https://doi.org/10.13031/aea.11992

Calcante, A., Fontanini, L., \& Mazzetto, F. (2013). Repair and maintenance costs of 4WD tractors in northern Italy. Trans. ASABE, 56(2), 355-362. https://doi.org/10.13031/2013.42660

Goering, C. E. (1992). Engine and tractor power (3rd Ed.). St. Joseph, MI: ASAE.

Hastie, T., Tibshirani, R., \& Friedman, J. (2008). The elements of statistical learning: Data mining, inference, and prediction (2nd Ed.). New York, NY: Springer-Verlag.

Hawkins, E. M., \& Buckmaster, D. R. (2015). Benchmarking costs of fixed-frame, articulated, and tracked tractors. Appl. Eng. Agric., 31(5), 741-745. https://doi.org/10.13031/aea.31.11074

Kunz, A. (2006). Development of a universal tractor transmission oil (UTTO) based on renewable raw materials. Materialwiss. Werkstofftech., 37(2), 191-201. https://doi.org/10.1002/mawe.200500984

Lips, M. (2013). Repair and maintenance costs for nine agricultural machine types. Trans. ASABE, 56(4), 1299-1307. https://doi.org/10.13031/trans.56.10083

Lovarelli, D., Bacenetti, J., \& Fiala, M. (2016). A new tool for life cycle inventories of agricultural machinery operations. J. Agric. Eng., 47(1), 40-53. https://doi.org/10.4081/jae.2016.480

Minitab. (2010). Minitab 17 Statistical Software. State College, PA: Minitab, Inc. Retrieved from www.minitab.com.

Molari, G., Molari, P. G., Pagliarani, S., \& Sedoni, E. (2008). Evaluation of oil flows for the lubrication of an agricultural tractor transmission. Trans. ASABE, 51(3), 791-796. https://doi.org/10.13031/2013.24516

Montgomery, D. C., Peck, E. A., \& Vining, C. G. (2001). Introduction to linear regression analysis (3rd Ed.). New York, NY: John Wiley \& Sons.

Moriasi, D. N., Arnold, J. G., Van Liew, M. W., Bingner, R. L., Harmel, R. D., \& Veith T., L. (2007). Model evaluation guidelines for systematic quantification of accuracy in watershed simulations. Trans. ASABE, 50(3), 885-900. 
https://doi.org/10.13031/2013.23153

Morris, J. (1988). Estimation of tractor repair and maintenance costs. J. Agric. Eng. Res., 41(3), 191-200. https://doi.org/10.1016/0021-8634(88)90178-3

Nemecek, T., \& Kagi, T. (2007). Life cycle inventories of agricultural production systems: Data v2.0 (2007). Ecoinvent Report No. 15. Zürich, Switzerland: Agroscope ReckenholzTänikon Research Station.. Retrieved from https://db.ecoinvent.org/reports/15_Agriculture.pdf

OECD. (2017). Code 2: OECD Standard code for the official testing of agricultural and forestry tractor performance. Paris, France: Organization for Economic Cooperation and Development. Retrieved from http://www.oecd.org/tad/code/02-oecd-tractorcodes-code-02.pdf
Rawlings, J. O., Pantula, S. G., \& Dickey, D. A. (2001). Applied regression analysis: A research tool (2nd Ed.). New York, NY: Springer-Verlag.

Schabenberger, O., \& Pierce, F. J. (2002). Contemporary statistical models for the plant and soil sciences. Boca Raton, FL: CRC Press.

Srivastava, A. K., Goering, C. E., Rohrbach, R., \& Buckmaster, D. R. (2006). Chapter 15: Machinery selection and management. In Engineering principles of agricultural machines (2nd Ed., pp. 525-552). St. Joseph, MI: ASABE. https://doi.org/10.13031/2013.41477

Wertz, K., Grisso, R., \& Von Bargen, K. (1990). A survey of ag tractor service intervals: Part I. Appl. Eng. Agric., 6(5), 537-541. https://doi.org/10.13031/2013.26424 